\title{
Editorial
}

\section{THE ROLE OF PEER REVIEWING IN THE WORLD OF OPEN ACCESS PUBLISHING, TODAY AND TOMORROW}

Joints is currently in its third year and, in the wake of two important milestones - its indexing in PubMed and the open access publication of all its scientific content through PubMed Central -, it now has a new Editorial Board. I am delighted to welcome our new Deputy Editor, Giuseppe Filardo, and the new Associate Editors, Antonio Gigante, Andrea Grasso, Vincenzo Condello and Vincenzo Madonna, as well as the new Editorial Board members, in particular the colleagues from many different parts of the world who have very willingly agreed to be part of what today can be considered a panel of international experts. I also wish to take this opportunity to thank those whose term on the Editorial Board has come to an end and whose enthusiasm and hard work have contributed greatly to the journal's growth and development. Thank you, all of you, for being prepared to devote a portion of your valuable time to reading the articles, written by others, that are submitted to us and require careful selection and reviewing.

Undoubtedly, one of the main problems for those who do peer reviewing work is the fact that the time they spend reading the articles of others is time that they cannot devote to writing their own, and when the invitations to review papers multiply uncontrollably they find themselves obliged to turn down requests, even ones from prestigious journals. Furthermore, a great deal of time is spent reading articles that, because of their poor quality, never reach publication. In this regard, there are two considerations to be made: the first is linked to the pressing and growing demand for reviews that is coming from new magazines. We are witnessing a continuous proliferation of magazines in every field of science journalism; online publication, an option that has removed the obligation to publish in print, has dramatically reduced production costs. This, in turn, has led to an increase in the number of publications and the number of articles published in each volume and, with it, a huge increase in requests to review papers. And yet, peer reviewing is, in most cases, an unpaid and voluntary activity that demands expertise, method and time. As a result, there are fewer and fewer reviewers available, both to meet the growing demand but also in general, and this means that all journals are drawing on the same resource (the body of reviewers who work for several journals contemporaneously). This has two possible consequences: either recognised reviewers become over burdened with work, or journals tend to enlist volunteer reviewers without first putting in place a proper process of verification and selection. In both cases, the result is often a loss of peer reviewing quality and less control over the quality of the end product.

The second consideration concerns merit, and it is linked to the growing need to recognize quality in today's sea of information information disclosed in increasing quantities and at an increasingly rapid rate. Basically, in an era in which readers/consumers of scientific information can be reached very easily and quickly, and in which many journals choose to be open access publications, and thus to allow anyone free and immediate access to their content, it is even more important to have an adequate literature selection and review process, able to go on playing a role in ensuring end product quality.

So, in today's virtual world in which any information can be shared without filters and in real time, can peer reviewing still be considered useful and necessary? What will its role be, when all publishers can choose to turn their publications into open access journals, a kin to open forums or scientific blogs where everyone is free to write, read and reply? Who will guarantee the scientific merit of a clinical trial and the validity of its conclusions? Who will guarantee the translational value of research conducted in a laboratory? Who will protect us from the overload of commercial information disguised as scientific research? The truth is that only competent and responsible peer reviewing, preserving and defending the ethical and scientific value of a journal, will be able to make a difference. 